\title{
US adolescent food intake trends from 1965 to 1996
}

Claude Cavadini, Anna Maria Siega-Riz, Barry M Popkin

\begin{abstract}
Aim-To examine adolescent food consumption trends in the United States with important chronic disease implications. Methods-Analysis of dietary intake data from four nationally representative United States Department of Agriculture surveys of individuals 11-18 years of age ( $\mathrm{n}=12$ 498).

Results-From 1965 to 1996 , a considerable shift in the adolescent diet occurred. Total energy intake decreased as did the proportion of energy from total fat $(39 \%$ to $32 \%)$ and saturated fat $(15 \%$ to $12 \%)$. Concurrent increases occurred in the consumption of higher fat potatoes and mixed dishes (pizza, macaroni cheese). Lower fat milks replaced higher fat milks but total milk consumption decreased by $36 \%$. This decrease was accompanied by an increase in consumption of soft drinks and noncitrus juices. An increase in high fat potato consumption led to an increase in vegetable intake but the number of servings for fruits and vegetables is still below the recommended five per day. Iron, folate, and calcium intakes continue to be below recommendations for girls.

Conclusions-These trends, far greater than for US adults, may compromise health of the future US population.

(Arch Dis Child 2000;83:18-24)
\end{abstract}

Keywords: nutrition; adolescents; national survey; diet

Adolescence is a critical period during which lifetime habits are established. Many teenagers are preoccupied by their physical characteristics and appearance, ${ }^{1}$ resulting in nutritional practices such as dieting or consuming fad foods. Dieting, a commonly occurring practice among adolescent girls, may be the cause of inadequate dietary intake and may have important health effects for selected nutrients such as calcium, iron, and folate. ${ }^{2}$ Some teenagers continue to exercise and become more involved in sports, while others stop and eventually begin to develop a sedentary life style. ${ }^{3}$ Many of the adolescent lifestyle habits may have severe consequences in the long run. For example, being overweight during adolescence is associated with increased risk for being overweight during adulthood ${ }^{45}$ as well as increased hypertension during adolescence, ${ }^{6}$ and more recently, with increased adult onset diabetes occurring during adolescence. ${ }^{7}$ The National Health and Nutrition Examination Surveys (NHANES) in the United States showed increasing prevalence of overweight not only in adults but also in adolescents, in particular over the last 15 years. ${ }^{8}$ Furthermore, we know from previous studies that blood pressure and cholesterol concentrations track from childhood into adulthood..$^{11}$ Excessive weight gain during childhood and adolescence is a determinant of adult cardiovascular risk and mortality. ${ }^{12} 13$ Similarly, inadequate fruit and vegetable intake may affect the prevalence of selected cancers. ${ }^{14}$ This study was initiated to provide a better understanding of adolescent food habits, and to follow food trends that may have implications for the later development of adult non-communicable diseases.

\section{Methods}

SURVEY DESIGN AND SAMPLE

From the initial sample of approximately 90000 individuals participating in four United States Department of Agriculture (USDA) surveys, adolescents aged 11 to 18 with dietary data were selected for this study. Of these 12498 adolescents, 3061 came from the 1965 and 6208 from the 1977-78 Nationwide Food Consumption Surveys (NFCS), and 1656 came from the 1989-91 and 1573 from the 1994-96 Continuing Survey of Food Intake by Individuals (CSFII). The USDA surveys from 1965 to 1991 contain stratified area probability samples of non-institutionalised US households in the 48 coterminous states and in all 50 states in 1994-96. The 1977, 1989-91, and 1994-96 surveyors conducted four data collection waves (winter, spring, summer, autumn), each surveying a different sample, whereas the 1965 survey collected individual dietary data in a single spring sample. These surveys were self weighting, multistage, stratified area samples of the US population. For each survey, response rates differed at the level of the primary sampling unit. Thus, weights based on response rates for each sample unit are used to permit inferences applicable to the total non-institutionalised US population. Detailed information on the methodology pertaining to each survey has been published previously. ${ }^{15-18}$

\section{DIETARY DATA}

Each survey included at least one in home, interviewer administered, 24 hour dietary recall. The 1977 and 1989-91 surveys also included two self administered one day food records. Information was collected on everything individuals ate at home or away. For our purpose of studying trends in dietary intake over time, we used only the first day of dietary intake information from each survey- the one day (24 hour) dietary recall. This method avoids the biasing of intake results that may 
Table 1 Sociodemographic characteristics for adolescents (aged 11-18) with dietary data from the four USDA surveys

\begin{tabular}{|c|c|c|c|c|}
\hline Characteristic & 1965 & 1977 & 1989-91 & 1994-96 \\
\hline No. of individuals & 3061 & 6208 & 1656 & 1573 \\
\hline$\%$ of males & 51.1 & 49.4 & 50.9 & 50.3 \\
\hline \multicolumn{5}{|l|}{ Race $(\%)^{\star}$} \\
\hline White & 82 & 76.2 & 74.9 & 66 \\
\hline Black & 15.8 & 15.8 & 16.6 & 16.3 \\
\hline Hispanic & NA & 7.1 & 8.5 & 12.9 \\
\hline Household size, mean (SEM) & $5.58(0.04)$ & $5.22(0.02)$ & $4.43(0.03)$ & $4.45(1.04)$ \\
\hline \multicolumn{5}{|l|}{ Distribution by region $(\%)$} \\
\hline Northeast & 22.4 & 23 & 20.3 & 18.1 \\
\hline North Central & 28.7 & 28.1 & 24.3 & 24.8 \\
\hline South & 34.4 & 31.5 & 36.1 & 35.2 \\
\hline West & 14.5 & 17.4 & 19.3 & 21.9 \\
\hline \multicolumn{5}{|l|}{ Distribution by urbanisation (\%) } \\
\hline Central city & NAt & 27.7 & 26.8 & 28.4 \\
\hline Suburban & NA & 38.5 & 47.2 & 48.8 \\
\hline Rural & 35.9 & 33.8 & 26 & 22.8 \\
\hline Household income, mean (SEM) & $\$ 7116(85)$ & $\$ 17517(159)$ & $\$ 40429(531)$ & $\$ 44635(712)$ \\
\hline \multicolumn{5}{|c|}{ Distribution by percentage of poverty (\%) } \\
\hline$\leqslant 185 \%$ & 56.3 & 37 & 33 & 37.1 \\
\hline $185-350 \%$ & 32.7 & 38.3 & 33.6 & 29.8 \\
\hline$>350 \%$ & 11 & 24.8 & 33.4 & 33 \\
\hline \multicolumn{5}{|l|}{ Body mass index (SEM) } \\
\hline $11-14$ year olds & $19.49(0.08)$ & $19.89(0.07)$ & $20.24(0.13)$ & $20.74(0.15)$ \\
\hline $15-18$ year olds & $21.35(0.08)$ & $21.40(0.06)$ & $22.26(0.15)$ & $22.76(0.17)$ \\
\hline
\end{tabular}

The four USDA surveys are the Nationwide Food Consumption Survey 1965 and 1977, and the Continuing Survey of Food Intake by Individuals 1989-91 and 1994-96.

$\star$ USDA began collecting data on Hispanic origin in 1977; the remaining percentage represents other minorities.

tIn 1965, USDA coded this variable as urban, rural non-farm, and rural farm. The only comparable variable we could create was rural by adding the two rural categories. The other $64 \%$ is thus a combination of central city and suburban.

occur because of the different dietary data collection methods used and different number of days of reported intake that were collected.

Two of the challenges in trends analysis include accounting for differences in how foods are defined over time, as well as characterising the nutrient contribution of each food. Food codes changed considerably (often for the same food) and technology to measure nutrients has changed over time. The authors have developed a number of ways to link foods coded and collected in the last decade with foods all the way back to 1965 . Values from the 1994 nutrient database were then applied to the three data sets prior to 1994 to provide consistently high quality estimates of nutrient values over time. In the most recent survey, the nutrient database specific to each survey year was used to calculate nutrient values in order to reflect changes in foods on the market.

This approach allows for the use of newer measures of nutrients and to consider shifts in food descriptors. True changes in the actual

Table 2 Selected nutrient intakes of 11-18 year olds with one day of dietary data from the four USDA surveys

\begin{tabular}{|c|c|c|c|c|}
\hline Nutrient & 1965 & 1977 & 1989-91 & 1994-96 \\
\hline Energy (MJ) & $9.92(0.16)^{\star} \dagger$ & $8.78(0.09)$ ฯ & $8.77(0.18)^{\star \star}$ & $9.58(0.18)$ \\
\hline Total fat, $\%$ of energy & $38.7(0.2)^{\star}+\ddagger$ & $37(0.2) \Phi$ & $34.3(0.4)^{\star \star}$ & $32.7(0.2)$ \\
\hline Saturated fat, $\%$ of energy & $15(0.1)^{\star}+\ddagger$ & $14.1(0.1) \S$ & $12.9(0.2)^{\star \star}$ & $11.6(0.1)$ \\
\hline Carbohydrate, $\%$ of energy & $46.3(0.3) \dagger \ddagger$ & $47.1(0.2) 59$ & $51.4(0.5)^{\star \star}$ & $54.2(0.3)$ \\
\hline Protein, \% of energy & $16.1(0.1)^{\star} \ddagger$ & $16.7(0.1)$ ऽ & $15.4(0.2)^{\star \star}$ & $14.2(0.1)$ \\
\hline Vitamin A (RE) & $1155(43.1) \dagger \ddagger$ & $1026(26.8)$ & $902(33.0)$ & $932(32.3)$ \\
\hline Vitamin C (mg) & $89(2.2)$ & $90(2.0)$ & $103(4.1)$ & $105(4.4)$ \\
\hline Iron (mg) & $14(0.2) \ddagger$ & $14(0.2) \Phi$ & $15(0.4)^{\star \star}$ & $17(0.4)$ \\
\hline Folacin $(\mu \mathrm{g})$ & $244(4.5)^{\star}$ & $265(4)$ & $272(7.4)$ & $274(8.3)$ \\
\hline Calcium (mg) & $1100(22.1)^{\star} \dagger \ddagger$ & $1009(15.6)$ & $974(23.6)$ & $960(18.6)$ \\
\hline Fibre (g) & $13.5(0.3) \ddagger$ & $13(0.2)$ & $14(0.3)$ & $15(0.4)$ \\
\hline
\end{tabular}

Results expressed as mean (SEM)

The four USDA surveys are the Nationwide Food Consumption Survey 1965 and 1977, and the Continuing Survey of Food Intake by Individuals 1989-91 and 1994-96.

*Significant differences between 1965 and 1977, p<0.001

$\dagger$ Significant differences between 1965 and $1989, \mathrm{p}<0.001$

$\ddagger$ Significant differences between 1965 and $1996, \mathrm{p}<0.001$

§Significant differences between 1977 and 1989, p<0.001

-Significant differences between 1977 and 1996, $\mathrm{p}<0.001$

$\star \star$ Significant differences between 1989 and $1996, \mathrm{p}<0.001$. nutrient content of foods over time will not be captured by use of a single nutrient composition table, and trends may be either over or under stated. In weighing the advantages and disadvantages of using different nutrient composition measures, the authors concluded that using the 1994 nutrient data provides a conservative measure of some of the nutrient trends in foods (for example, fat) and allows for the examination of trends in several nutrients (for example, fibre) that would not have been possible otherwise.

The Food Guide Pyramid database released by USDA with the 1994-96 survey was used to calculate the servings of fruit, vegetables, milk, and grains as well as the ounces of lean meat equivalents for all four surveys. ${ }^{19}$ The same linking program used to apply the 1994 nutrient values back in time was used for these calculations.

\section{FOOD GROUPING SCHEME}

In order to examine changes in the quantity of foods consumed over time, we developed a University of North Carolina (UNC food grouping system) which aggregates the 4000 or so foods consumed. This is a system which separates virtually all foods in USDA's Individual Food Consumption Surveys into 74 useful descriptive and nutrient based groups. Initially major food groups were based on food groupings used by USDA, then fat and dietary fibre compositions were used to develop more refined food groupings, and nutrient thresholds were used to separate major food groups into more distinct, nutrient based food groups (available on request).

STATISTICAL ANALYSIS

Descriptive statistics were generated for each survey year using the SUDAAN version 7.51 (Research Triangle Institute, Research Triangle Park, North Carolina) software package to 
appropriately correct the standard errors for sample design effects and for applying survey weights. Differences in nutrient and servings of the Food Guide Pyramid means between years were then tested for significance in SAS version 6.12 (SAS Institute, Cary, North Carolina) using a Student's $t$ test. A more stringent $\mathrm{p}$ value of less than 0.001 was used to denote statistical difference. Nutrient values were compared to the most recent recommendations made by the Food and Nutrition Board (recommended dietary allowances (RDA) or recommended dietary intake (RDI)) and expressed as a percentage of the recommendations specific for each age and gender grouping. ${ }^{20}$

\section{Results}

Table 1 shows sociodemographic information for the individuals in the study by survey year. Important trends of interest are the increase in mean household income, the subsequently

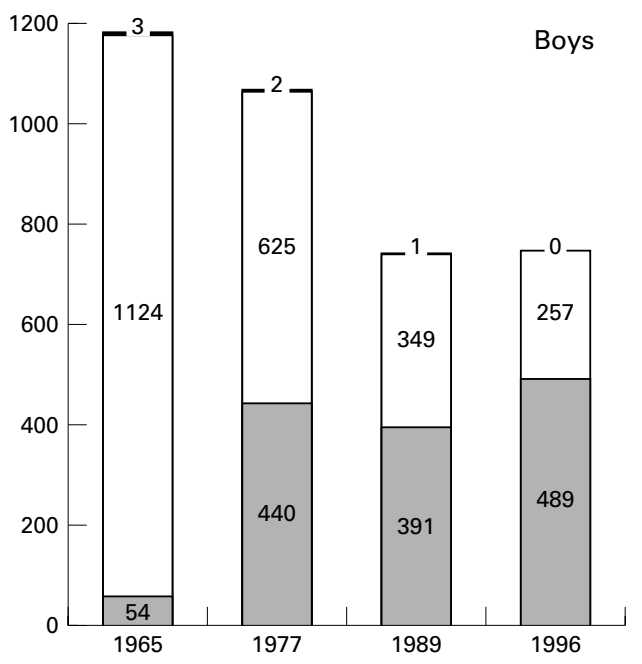

more even distribution of percentage of poverty starting in 1977, and the increasing number of Hispanics represented in the survey, as well as the increase in body mass index for both younger and older adolescents.

Energy intake decreased over the years, with the greatest drop occurring from 1965 to 1977 (table 2). The data for all four years showed typical differences in pattern of energy intake, with boys consuming higher amounts than girls (data not shown). Table 2 also shows the proportion of energy from total fat, saturated fat, carbohydrate, and protein. A steady decline in fats and protein as a proportion of total energy intake occurred in the diet over time, which was compensated by an increase in carbohydrate intake. Gender did not affect the distribution of macronutrients (data not shown). Between 1989-91 and 1994-96, fat intake increased from 80 to $83 \mathrm{~g} /$ day, saturated fat stayed at $30 \mathrm{~g} /$ day, carbohydrate increased from 270 to $311 \mathrm{~g} /$ day, and protein intake

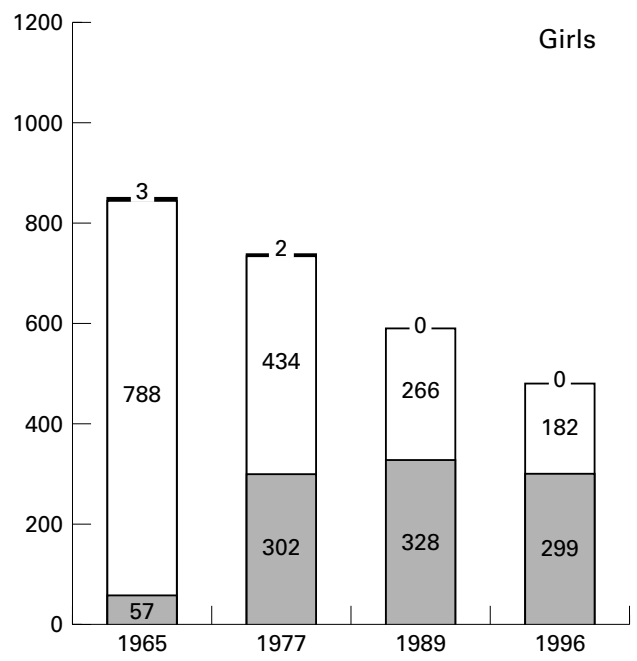

High fat $\square$ Medium fat $\square$ Low fat

Figure 1 Trends in milk consumption among US adolescents in the USDA surveys, 1965-96.
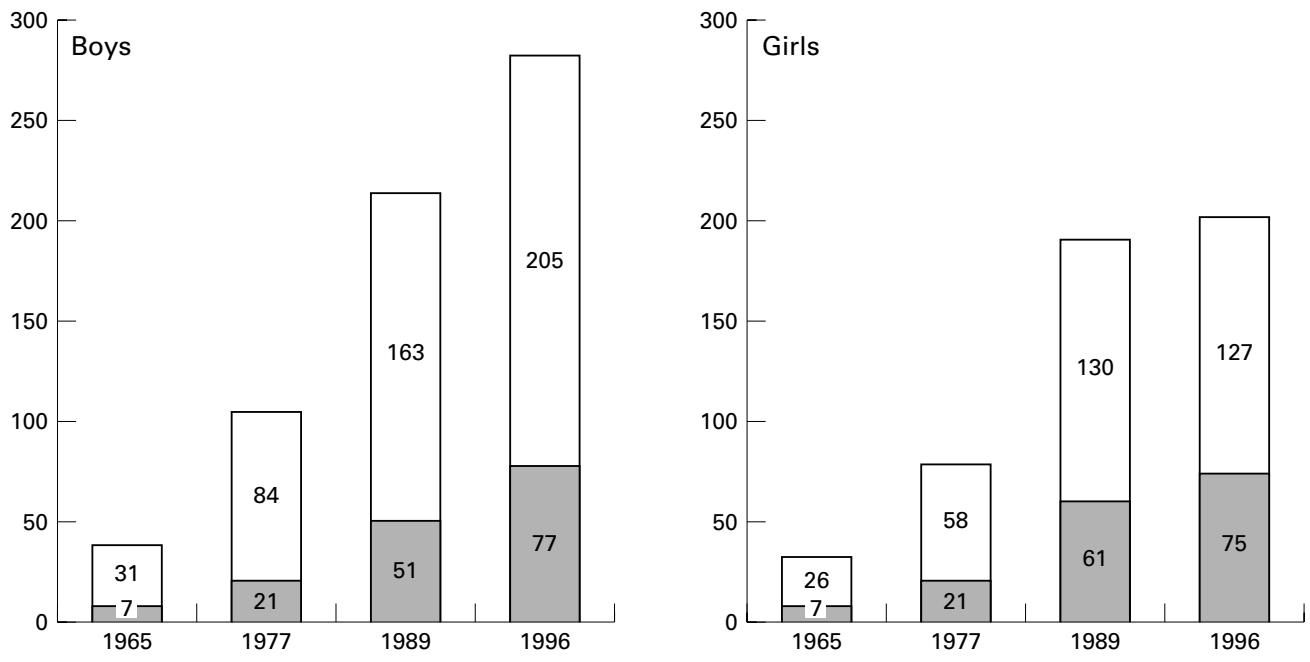

High fat grain BM $\square$ Low fat grain BM

Figure 2 Trends in consumption of grain based mixed dishes among US adolescents in the USDA surveys, $1965-96$. 
remained relatively unchanged (increased from 81 to $82 \mathrm{~g} /$ day).

Other nutrients of interest that we examined included vitamins $\mathrm{A}$ and $\mathrm{C}$, iron, folacin, calcium, and fibre. On average, only vitamin A and calcium concentrations decreased over time, so that in 1996 the mean percentage of the recommended intakes being met for each nutrient was $103 \%$ and $74 \%$ respectively. The other four nutrient concentrations increased over time, and all but folacin and fibre met the most recent dietary recommendations. Some slight differences by gender existed. For example, in 1996, $40 \%$ of females met the recommended dietary intakes for iron, $20 \%$ for calcium, and $17 \%$ for folate. For males, $75 \%$ met the recommendations for iron and approximately one third met the recommendations for calcium and folate.

The most interesting food group consumption trends are shown in figs $1,2,3,4$, and 5 by

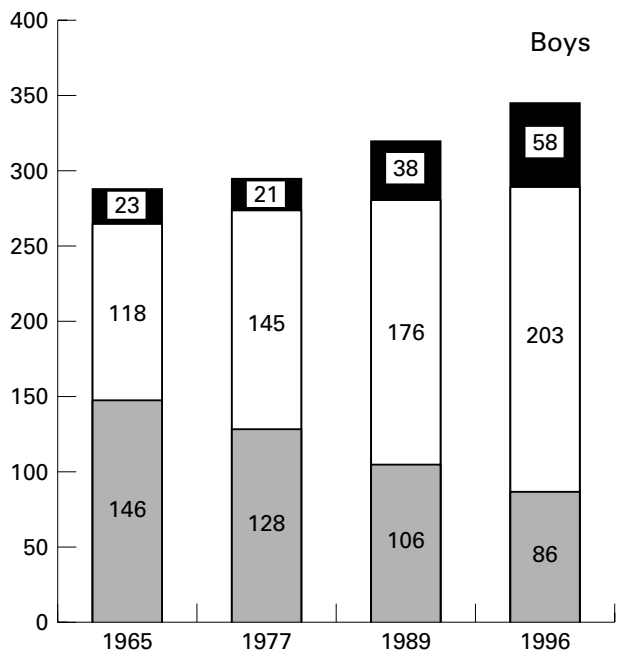

gender and in table 3 for the entire age group (data for other foods are available on request). The figures reflect the per capita grams of food consumed per day using the UNC food groups. The table presents actual servings of food groups or, as in the case of meat, ounces of lean meat equivalents using the UDSA Food Guide Pyramid database. The results show a decline in milk consumption that was not compensated for by an increase in other dairy products. Low fat milk was substituted for whole milk (medium fat source). Grain intake increased but primarily from high fat mixed dishes such as pizza, macaroni cheese, and certain ethnic foods. Raw fruit consumption declined steadily but juice consumption increased; this accounts for the relatively stable number of servings in table 3. Figure 4 shows a decrease in the grammes consumed of dark green and orange vegetables from 1965 to 1989 and then an increase from 1989 to 1996 . Since 1965 the

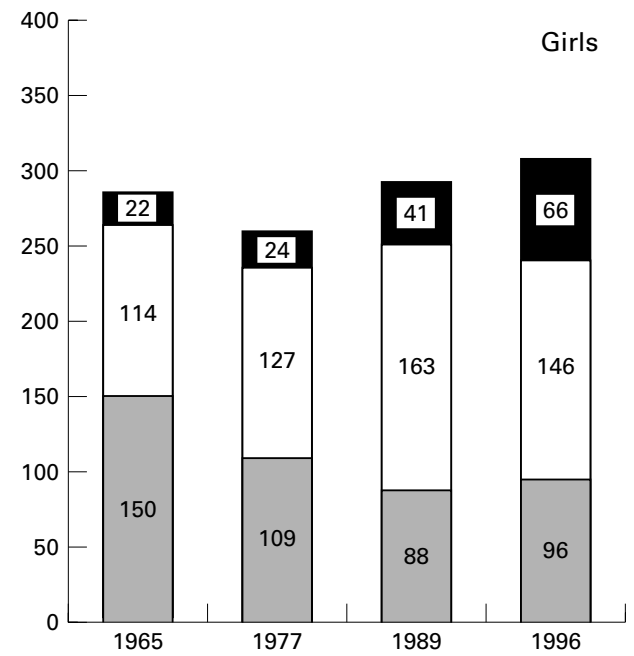

Other juices $\square$ Citrus fruit and juices $\square$ Low fibre fruits

Figure 3 Trends in fruit consumption among US adolescents in the USDA surveys, 1965-96.
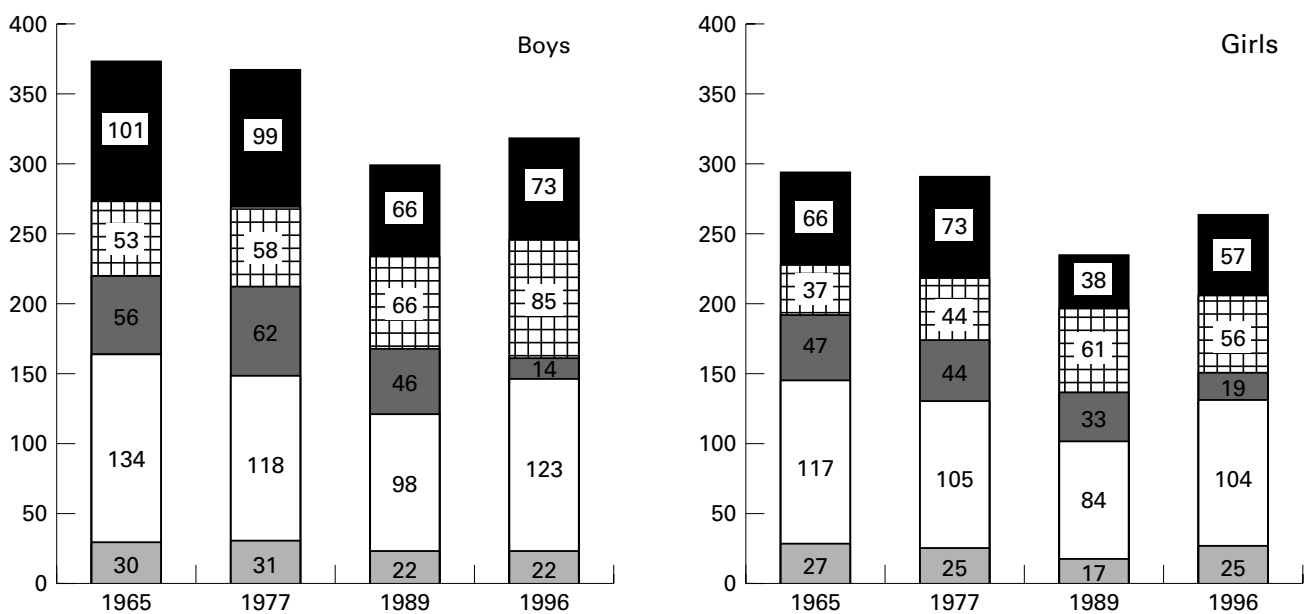

Potato-low fat Potato-high fat $\square$ Medium fibre $\square$ Low fibre

Dark green and orange

Figure 4 Trends in vegetable consumption among US adolescents in the USDA surveys, 1965-96. 

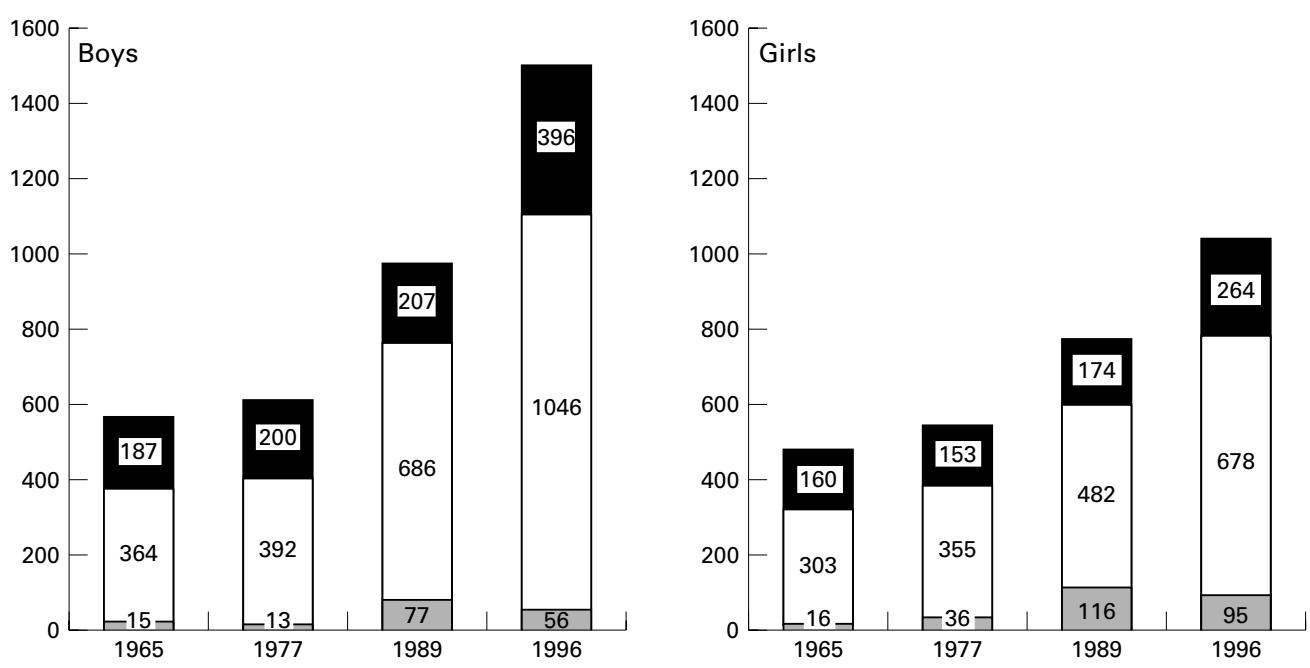

Fruit drinks $\square$ Soft drinks $\square$ Diet soft drinks

Figure 5 Trends in beverage consumption among US adolescents in the USDA surveys, 1965-96.

grammes of high fat potatoes consumed have increased. By 1996 white potatoes account for half of the vegetable consumption, whereas in 1965 it only accounted for a third (table 3). Thus the overall vegetable consumption has increased since 1965 for this population. The lean meat and egg consumption decreased over time. Finally, soft drinks consumption rose sharply.

\section{Discussion}

This is the first study to examine dietary trends among US adolescents which uses actual dietary intake data that are comparable from a nationally representative sample over three decades. The small sample size for nonHispanic African-American and Hispanic subgroups forced us to focus on the total adolescent population. Our results show a decrease in total energy intake and total fat over the period studied, the latter of which is positive, but also a decrease in raw fruits, nonpotato sources of vegetables, and calcium rich

Table 3 Mean Food Guide Pyramid servings of 11-18 years olds with one day of dietary data from the four USDA surveys

\begin{tabular}{|c|c|c|c|c|}
\hline Food group & 1965 & 1977 & 1989-91 & $1994-96$ \\
\hline Dairy & $2.5(0.07) \ddagger$ & $2.3(0.05)$ & $2.2(0.07)$ & $2.0(0.05)$ \\
\hline Grain & $6.6(0.12)^{\star} \ddagger$ & $6.2(0.07) 5$ & $7.1(0.20)$ & $7.7(0.11)$ \\
\hline Fruit (incl. juices) & $1.4(0.06)$ & $1.1(0.04)$ & $1.2(0.07)$ & $1.4(0.04)$ \\
\hline Vegetables (all) & $2.7(0.06)^{\star} \ddagger$ & $3.0(0.06)$ & $3.0(0.10)^{\star \star}$ & $3.3(0.07)$ \\
\hline White potato & $0.8(0.02)^{\star} \dagger \ddagger$ & $1.1(0.03)$ - & $1.3(0.08)$ & $1.5(0.06)$ \\
\hline \multicolumn{5}{|l|}{ Meat (ounces) } \\
\hline Meat, poultry, and fish $+\dagger$ & $5.6(0.12)^{\star} \dagger \ddagger$ & $5.0(0.07) \circlearrowleft$ & $4.0(0.10)$ & $4.0(0.09)$ \\
\hline Eggs执 & $0.7(0.02)^{\star} \dagger \ddagger$ & 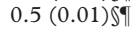 & $0.3(0.03)$ & $0.3(0.02)$ \\
\hline Nuts and seeds $\$ \llbracket$ & $0.3(0.03)^{\star}+\ddagger$ & $0.1(0.01)$ & $0.1(0.02)$ & $0.2(0.01)$ \\
\hline
\end{tabular}

Results expressed as mean (SEM)

The four USDA surveys are the Nationwide Food Consumption Survey 1965 and 1977, and the Continuing Survey of Food Intake by Individuals 1989-91 and 1994-96.

*Significant differences between 1965 and $1977, \mathrm{p}<0.001$

†Significant differences between 1965 and 1989, p<0.001

¥Significant differences between 1965 and 1996, p<0.001.

Significant differences between 1977 and $1989, \mathrm{p}<0.001$

$\star \star$ Significant differences between 1989 and 1996, p<0.001.

††Ounces of cooked lean meat equivalents from beef, pork, veal, lamb, game; frankfurters, sausages, and luncheon meats; poultry; and fish and shellfish.

t\$ne egg is equivalent to one ounce of cooked lean meat. Includes eggs and egg substitutes.

\$SOne third cup of nuts and one fourth cup of seeds is equivalent to one ounce of cooked lean meat. dairy sources. Soft drink consumption greatly increased. Many national surveys that focus on adolescents, such as the Youth Risk Behavior Surveillance System (funded by the Centers for Disease Control) and Prevention and the National Longitudinal Survey of Adolescent Health (funded by the National Institutes of Health) lack the appropriate dietary data to quantify these trends.

The amounts of total energy intake observed between 1965 and 1996 were below recommendations and decreased with time in each age and gender group. Overall there was a decline of $17 \%$ in energy over this 30 year time period. In the last period between 1989-91 and 1994-96, mean energy intake increased by $9 \%$. Future surveys are needed to show if this is a real trend or related to the major changes in methodology between these two surveys. Both the NHANES and CSFII reported this increased intake but both changed their approaches to provide much more in depth probing for dietary intake in order to avoid some of the undercounting found in the past. The decreased energy intake seems counter intuitive in view of the rising prevalence of overweight and obesity among adolescents which has been shown by other studies. ${ }^{8921}$ The most likely explanation, apart from the $1989-969 \%$ increase in total energy intake is a concomitant decrease in energy expenditure caused by a decrease in physical activity. ${ }^{3}$ As children age, the majority decrease their physical activity. ${ }^{22-24}$ Another explanation is differential under reporting by year of the survey, with more under reporting occurring in 1996 than in 1965. However, with each survey, the methodology for collecting the dietary information improved; in the latest survey more probing and a multipass approach were used to decrease the amount of under reporting. ${ }^{25}$ Therefore, we would suspect that more under reporting occurred in 1965 than in 1996, which would have lead to underestimating the difference in energy over time. 
As with older Americans, adolescents had a higher percentage of energy still coming from fat than the present dietary guidelines recommend. ${ }^{26} 27$ The proportion of energy coming from carbohydrate and protein was within recommendations. In terms of the absolute intake of food, however, we found that between 1989 and 1996, total fat intake increased by $4 \%$, saturated fat remained stable, carbohydrate intake increased by $15 \%$, and protein by $1 \%$. Intakes of fibre (the recommendation being more than $10 \mathrm{~g}$ per $4.18 \mathrm{MJ}){ }^{28}$ folate, and calcium for the entire age group and iron for females were lower than optimal for proper growth and development during adolescence.

Several of these trends combined create important nutritional problems. Inadequate fibre consumption and decreasing raw fruit and non-potato vegetable consumption are major concerns. Others in the field have substantiated these findings for this age group and for younger ages. ${ }^{29} 30$ This population does not consume other sources of fibre such as whole grains, pasta, rice, bread, and high fibre cereals in sufficient quantities to make a difference in the total fibre intake. Thus, not only are adolescents at risk of chronic diseases because of low fibre intake but also because of low antioxidant and non-nutrient sources of plant foods, which may serve as protective factors for certain cancers. ${ }^{14}$

Another example of a potential nutritional problem is the decreased milk consumption, which has not been replaced by other rich sources of calcium but rather by soft drinks and non-citrus juices and drinks. Decreased milk consumption has occurred for both males and females but is of most concern for females, who may be at greater risk of developing osteoporosis later in life. Adolescence is the optimum period to increase bone density. ${ }^{2}$ This trend, coupled with the low dark green and orange vegetable consumption among adolescents, may be more problematic than once thought. Preliminary findings suggest that this dietary behaviour leads to increased phosphorus excretion, which subsequently may compromise bone building and maintenance. ${ }^{31}$ All age groups are susceptible to dental caries and hyperlipidaemia, two nutritional consequences of increased simple carbohydrate intake generated by increased soft drink consumption. ${ }^{32}$

Another area of concern is the low intake of dietary folate and iron for females. If these adolescents with such low intakes become pregnant, their risks of iron deficiency anaemia and having an infant with neural tube defects are increased. More nutrition intervention strategies are needed to improve the intakes of these nutrients. Recommending increased supplement use and fortification are key options.

In conclusion, these results show food consumption trends that are compromising the nutritional and health status of US adolescents and may contribute to important increases in nutrition related chronic diseases. Given our increasing understanding of the role that diet and body composition play in preventing disease and promoting a higher quality of life, these results provide a clearer basis for intervention during adolescence to instil proper dietary habits.

The Nestlé Research Center is thanked for providing financial support for this study. We thank Dr Henri Dirren for initiating the collaboration between Nestlé and UNC-CH, Dan Blanchette and Terri Carson for their programming assistance, and Frances Dancy for support in administrative matters.

1 Field AE, Cheung L, Wolf AM, Herzog DB, Gortmaker SL, Colditz GA. Exposure to the mass media and weight concerns among girls. Pediatrics 1999;103:E36.

2 Bonjour JP, Carrie AL, Ferrari S, et al. Calcium-enriched foods and bone mass growth in prepubertal girls: a randomized, double-blind, placebo-controlled trial. 7 Clin Invest 1997;99:1287-94.

3 Gordon-Larsen P, McMurray RG, Popkin BM. Adolescent physical activity and inactivity vary by ethnicity: the national longitudinal study of adolescent health. $\mathcal{F}$ Pediatr 1999;135:301-6.

4 Guo S, Roche A, Chumlea W, et al. The predictive value of childhood body mass index values for overweight at age 35 . Am 7 Clin Nutr 1994;59:810-19.

5 Diet WH, Childhood weight affects adult morbidity and mortality. F Nutr 1998;128:411S-14S

6 Urbina EM, Gidding SS, Bao W, Pickoff AS, Berdusis K, Berenson GS. Effect of body size, ponderosity, and blood pressure on left ventricular growth in children and young adults in the Bogalusa Heart Study. Circulation 1995;91: 2400-6.

7 Pinhas-Hamiel O, Dolan LM, Daniels SR, Standiford D, Khoury PR, Zeitler P. Increased incidence of non-insulindependent diabetes mellitus among adolescents. $\mathcal{F}$ Pediatr 1996;128:608-15.

8 Kuczmarski RJ, Flegal KM, Campbell SM, Johnson CL. Increasing prevalence of overweight among US adults. IAMA 1994;272:205-11.

9 Troiano RP, Flegal KM. Overweight children and adolescents: description, epidemiology and demographics. adolescents: description, epicen

10 Berenson GS, McMahan CA, Vorrs AW, et al. Cardiovascular risk factors in children, the early natural history of atherosclerosis and essential hypertension. New York: Oxford University Press, 1980.

11 Nicklas TA, Webber LS, Srinivasan SR, Berenson GS. Secular trends in dietary intakes and cardiovascular risk factors of 10-y-old children: The Bogalusa Heart Study (1973-1988). Am f Clin Nutr 1993;57:930-7.

12 Sinaiko AR, Donahue RP, Jacobs DR, Prineas RJ. Relation of weight and rate of increase in weight during childhood and adolescence to body size, blood pressure, fasting insulin and lipids in young adults. Circulation 1999; 99:1471-6.

13 Stevens J, Cai J, Pamuk ER, Williamson DF, Thun MJ, Wood $\mathrm{IL}$. The effect of age on the association between body-mass index and mortality. N Engl f Med 1998;338:1-7.

14 La Vecchia C, Tavani A. Fruit and vegetables, and human cancer. Eur f Cancer Prev 1998;7:3-8.

15 USDA. Food and nutrient intake of individuals in the US, Spring 1965. Washington, DC: USDA, 1972.

16 USDA. Human Nutrition Information Service. Food intakes: individuals in 48 states, year 1977-78. Nationwide Food Consumption Survey 1977-78, Rep I-1. National Technical Information Service, 5285 Port Royal Road, Springfield, VA 22161. Technical report: accession no. PB91103523INZ, 1983.

17 Tippett KS, Mickle SJ, Golman JD, et al. Food and nutrient intakes by individuals in the United States, 1 day, 1989-91. Continuing survey of food intakes by individuals 1989-91, Nationwide Food Surveys report no. 91-2. Washington, DC: US Department of Agriculture, Agriculture Research Service, 1995

18 Tippett KS, Cypel YS. Design and operation: the continuing survey of food intakes by individuals and the diet and health knowledge survey 1994-96. Continuing survey of food intakes by individuals 1994-96, Nationwide Food Surveys report no. 96-1. Washsington, DC: US Department of Agriculno. 96-1. Washsington, DC: US Depart

19 USDA. Agricultural Research Service. 1994-96 continuing survey of food intakes by individuals and diet and health nowledge survey. CD-ROM, accession number: PB98500457, 1998 [Available from the National Technical Information Service at 1-800-553-6847].

20 Report of the Standing Committee on the Scientific Evaluation of Dietary Reference Intakes, Food and Nutrition Board, Institute of Medicine. Available at the National Academy press web site: http://www.nap.edu/ readingroom

21 Freedman DS, Srinivasan SR, Valdez RA, Williamson DF, Berenson GS. Secular increases in relative weight and adiposity among children over two decades: the Bogalusa posity among children over two decart Study. Pediatrics 1997;99:420-6.

22 Baranowski T, Thompson WO, DuRant RH, Baranowski J, Puhl J. Observations on physical activity in physical locations: age, gender, ethnicity, and month effects. Res $Q$ locations: age, gender, ethnicity,
Exerc Sport 1993;64:127-33. 
23 Gordon-Larsen P, McMurray RG, Popkin BM. The environment significantly affects teen activity and inactivity: the national longitudinal study of adolescen health. Unpublished manuscript, 1999

24 Narring F, Berthoud A, Cauderay M, Favre M, Michaud $\mathrm{PA}$. Condition physique et pratiques sportives des jeunes dans le canton de Vaud. Lausanne: Institut universitaire de médecine sociale et préventive, 1997.

25 Guenther PM, DeMaio TJ, Ingwersen LA, Verlin M. The multi-pass approach for the 24-hour recall in the Continuing Survey of Food Intakes by Individuals (CSFII) 1994-96. FASEB F 1996;10:A198.

26 Popkin BM, Siega-Riz AM, Haines PS. A comparison of dietary trends between racial and socioeconomic groups in the United States. N Engl F Med 1996;335:716-20.

27 Wilkinson-Enns C, Goldman JD, Cook A. Trends in food and nutrient intakes by adults: NFCS 1977-78, CSFI 1989-91, and CSFII 1994-95. Family Economic Nutrition Review 1997;10:2-15.
28 A summary of conference recommendations on dietary fiber in childhood. Conference on Dietary Fiber in Childhood, New York, 24 May 1994. Pediatrics 1995;96(suppl): $1023-8$

29 Neumark-Sztainer D, Story M, Resnick M, Blum R. Correlates of inadequate fruit and vegetable consumption among adolescents. Prev Med 1996;25:497-505.

30 Nicklas T, Myers L, Berenson G. Dietary fiber intake of children: The Bogalusa Heart Study. Pediatrics 1995; 96(suppl): $988-94$.

31 Milne DB, Nielsen FH. Dietary magnesium affects macromineral metabolism in men. FASEB $\mathcal{f}$ 1998;12: A588.

32 Guesry PR. The nutritional role of soft drinks during childhood and adolescence. In: Ballabriga A, ed. Feeding from toddlers to adolescence. Nestle Nutrition Workshop Series, Vol. 37. Philadelphia: Nestec Ltd, Vevey/Lippincott-Raven Publishers; 1996.

\section{Better burns survival}

Children, particularly those under the age of 4 years, have had a worse prognosis following burns than have adults. Recent publications have shown that survival from severe burns has improved in adults but there has been no corresponding paediatric data. Now such data have been provided from a burns unit in Boston, USA (Robert L Sheridan et al. Archives of Pediatrics and Adolescent Medicine 2000;154:245-9).

They reported their results for two seven year periods, 1974-80 and 1991-97. In the first period 678 children were admitted with burns and in the second 1150 . Nine children who died within 24 hours were excluded from further analysis. Burns were categorised according to percentage of total body surface area involved: mild $(<40 \%)$, moderate $(40-59 \%)$, or severe $(60 \%$ or greater). The proportions in these categories were $80 \%, 10 \%$, and $10 \%$ in $1974-80$ and $92 \%, 4 \%$, and $4 \%$ in 1991-97. Mortality in the three categories was $0.6 \%, 8 \%$, and $33 \%$ during the first period and $0 \%, 0 \%$, and $14 \%$ in the second.

In the earlier period most deaths $(91 \%)$ were caused by late sepsis and multiple organ failure; in the later period only $33 \%$ of deaths were attributed to that cause. Between 1991-97, 676 (59\%) of the children admitted were less than 4 years old and 17 of these had severe burns but none died. Between 1974-80, $43 \%$ of the deaths had been in this age group.

Improved management of burns in children has resulted in much improved survival, especially in younger children.

ARCHIVIST 
PostScript

LETTERS

If you have a burning desire to respond to a paper published in $A D C$ or $F \mathscr{N} N$, why not make use of our "rapid response" option? Log on to our website (www.archdischild. com), find the paper that interests you, click on "full text" and send your response by email by clicking on "submit a response". Providing it isn't libellous or obscene, it will be posted within seven days. You can retrieve it by clicking on "read eLetters" on our homepage.

The editors will decide, as before, whether to also publish it in a future paper issue.

\section{C difficile induced pneumatosis} intestinalis in a neutropenic child

A 4 year old boy presented with a 24 hour history of fever, cramping central abdominal pain with distension, and bloody diarrhoeal stools. He had developed acute myeloblastic leukaemia at the age of 1 . He eventually required a matched unrelated graft which engrafted poorly, and subsequently developed graft versus host disease (GVHD). He was currently neutropenic.

Temperature was $38.5^{\circ} \mathrm{C}$, pulse $150 / \mathrm{min}$; he had abdominal distension and tenderness but no ascites.

An abdominal film (fig l) revealed dilatation of the colon with gaseous linear tramlining of the bowel wall consistent with pneumatosis intestinalis (PI). Stools were positive for Clostridium difficile toxin A. PI resolved with bowel rest, intravenous fluids, meropenem, and metronidazole but he later died of relapsed leukaemia.

PI is described in children in Crohn's disease, ${ }^{1}$ ulcerative colitis, ${ }^{2}$ leukaemia, trauma, ${ }^{4} \mathrm{HIV},{ }^{5}$ and GVHD after BMT. ${ }^{6} \mathrm{C}$ difficile, pseudomembranous colitis, and PI are reported in an immunocompetent adult

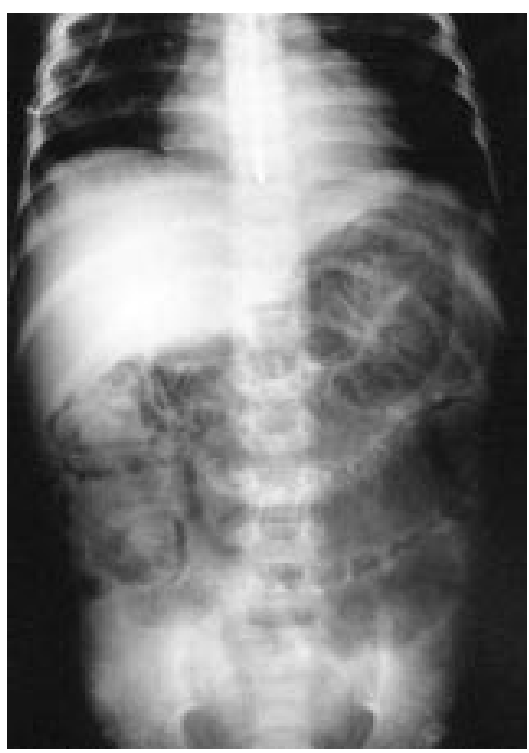

Figure 1 Abdominal film showing

dilatation of the colon and PI.

patient. ${ }^{7}$ Conservative management is usually successful but acidosis and portal gas are associated with a poor outcome.

P M Gillett

R K Russell

D C Wilson

Department of Gastroenterology and Nutrition Royal Hospital for Sick Children, Sciennes Road, Edinburgh EH9 1LF, Scotland, UK peter.gillett@luht.scot.nhs.uk

A E Thomas

Department of Haematology, Royal Hospital for Sick Children

\section{References}

1 Dubinsky MC, Deslandres $C$, Patriquin $\mathrm{H}$ Seidman EG. Pneumatosis intestinalis and colocolic intussusception complicating Crohn's disease. J Pediatr Gastroenterol Nutr 2000;30:96-8.
2 David O, Jakate S. Pneumatosis intestinalis in a 6-year-old girl with ulcerative colitis. Arch Pathol Lab Med 1999; 123:354-7.

3 Choo-Kang LR, Benson J, Fry T, et al. Pneumatosis cystoides intestinalis with labial crepitus in an infant with acute lymphoblastic leukemia. J Pediatr Gastroenterol Nutr 1999:28:442-5

4 Gurland B, Dolgin SE, Schlasko E, et al. Pneumatosis intestinalis and portal vein gas after blunt abdominal trauma. J Pediatr Surg 1998;33:1309-11.

5 Burton EM, Mercado-Deane MG, Patel K. Pneumatosis intestinalis in a child with AIDS and pseudomembranous colitis. Pediatr Radiol 1994;24:609-10.

6 Yeager AM, Kanof ME, Kramer SS, et al.

Pneumatosis intestinalis in children after allogeneic bone marrow transplantation. Pediatr Radiol 1987; 17:18-22.

7 Kreiss C, Forohar F, Smithline AE, et al. Pneumatosis intestinalis complicating $C$. difficile pseudomembranous colitis. Am J Gastroenterol 1999;94:2560-1.

8 Kurbekov AC, Sondheimer JM. Pneumatosis intestinalis in non-neonatal pediatric patients. Pediatrics 2001:108:402-6.

\section{CORRECTION}

We would like to acknowledge an error that was made in our article previously published in the journal (Arch Dis Child 2000;83:18-24). The absolute amount of grams consumed per day for the figures presented in the article were incorrect. An error was made in calculating the mean intake when the age groups (11-14 and 15-18) were combined. The corrected amounts are listed in the following table. This error does not change the trends or interpretation of results previously reported. A Maria Siega-Riz and B Popkin apologise for this unfortunate circumstance.

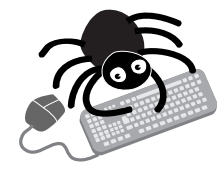

Please see the Archives website (www.archdischild.com) to view the corrected figures. 